\title{
Testing Uncovered Interest Rate Parity for Pakistan
}

\author{
ZINAZ AISHA \\ PhD Scholar, Applied Economics Research Centre, University of Karachi / Assistant Professor, Sardar \\ Bahadur Khan Women's University Quetta. \\ Email: zinaz aisha@yahoo.com \\ Tel: +923218018439
}

MUHAMMAD OMER

Joint Director Economic Policy Review Department, State Bank of Pakistan, Karachi Pakistan.

Email:Muhammad.omer@sbp.org.pk

Tel: +923012506195

\begin{abstract}
This paper provides direct empirical assessment of Uncovered Interest Rate Parity (UIP) for Pakistan. To Test UIP, wide range of maturities have been used and for estimation purpose, we used Johansen cointegration and Dynamic Ordinary Least Square (DOLS). We find that UIP does not hold for short to medium term maturities. However for the long term maturities i.e., 10-year, the result showes that the UIP holds. It means the exchange rate is better predicted by the long term interest rates. These findings suggest that the interventions in the foreign exchange market distort the price discovery mechanism of the foreign currency in the short to medium term. In the long run, however, the market fundamentals dictate the price discovery guiding the exchange rate to converge to its long run equilibrium.

Keywords: UIP, Johansen Cointegration, DOLS, Foreign Exchange Market, Price Discovery Mechanism.

\section{Introduction}

Uncovered interest parity (UIP) states that the expected change in the spot exchange rate over the specific period of time must be equivalent to the nominal interest rate differential between the similar underlying assets in the two currencies (Chin, 2007; Lily and Kogid,2011). Validating UIP remains challenging as it requires conditions, such as deep financial markets, free capital flows, and flexible exchange rate that are hardly fulfilled together, specifically in the developing economies. Despite its notoriety, UIP remains appealing to the academics and the policy makers alike, as it becomes an integral part of the theoretical and empirical macroeconomic models involving exchange rate.

Pakistan is not an exception, where researchers have used UIP as a building block for all dynamic macroeconomic models, without assessing its validity for this economy. Though available literature [For example, Frankel and Poonawala (2006); Sarmidi et al. (2011); Alper et al.(2007)] guides that UIP generally holds in developing and the emerging market economies, the hypothesis has hardly been tested directly for Pakistan to provide sound basis for its inclusion in Pakistan specific models. The skepticism is borne by the existing conditions that are not conducive for holding of UIP in Pakistan. For example, neither the foreign exchange market in the country has depth, nor capital mobility is perfect in any sense. More importantly, historically the exchange rate in Pakistan remained fixed or under managed floating regime; both are not flexible enough to accommodate swift convergence of exchange rate to its long run equilibrium.
\end{abstract}


This research is, therefore, an attempt to contribute to the literature by providing direct empirical assessment of UIP hypothesis for Pakistan. Scarce literature on Pakistan shows that this hypothesis is tested either jointly with the purchasing power parity or with the forward risk premium like Arshed and Haseeb (2013); Rashid and Husain (2012); Rashid (2012) have prominent work in this regard. These procedures not only assess indirectly whether UIP is holding or not, but also provides direct evaluation if rational expectation hypothesis holds in the foreign exchange market. Our research, instead on divulging the rational expectation hypothesis focuses solely on UIP by using actual exchange rate instead of the future expected exchange rate.

For the UIP assessment, US dollar exchange rate against Pak rupee has been used as Pakistan current and financial accounts flows are US dollar denominated. Our monthly data starts from March 2003, and ends at March 2019. The choice of the starting period is hinged on foreign exchange market consideration that largely remained unstable during 2000-2002 due to frequent experiment with various exchange rate regimes. For testing of UIP hypothesis, wide array of money market instruments with maturities that have range from 1-month to 10-years have been used. For estimation purpose, we used Johansen Cointegration and Dynamic Ordinary Least Square (DOLS).

Our result suggests that the UIP doesn't hold for Pakistan for short to medium term maturities. However, for the long term maturities i.e., 10-year, the result shows that the UIP holds. Our result finds support from Chinn and Meredith (2004) and Cheung et al. (2005); both concluded that the exchange rate is better predicted by the long term interest rates. These findings suggest that the interventions in the foreign exchange market distort the price discovery mechanism of the foreign currency in the short to medium term. In the long run, however, the market fundamentals dictate the price discovery guiding the exchange rate to converge to its long run equilibrium.

The remaining paper is structured as follow. Section 2 discusses stylized facts about Pakistan's economy, Section 3 reviews the literature available on UIP, Section 4 describes background theory and methodology, Section 5 includes results and their discussion, Section 6 is about the conclusion of the paper.

\section{Stylized facts about Pakistan's Exchange Rate and Interest Rate}

From its inception, in August 1947, Pakistan fixed its exchange rate with pound sterling (GBP) until September 1971. Despite maintaining fixed exchange rate, Pakistan didn't follow when UK devalued GBP in 1949 and 1967, leading to appreciation in Pak rupee against Pound sterling. In 1971, Pakistan fixed its currency against the USD after delinking from GBP. In between 1971 and 1982, the country infrequently changed the parity of the Pak rupees exchange rate against US dollar. Finally, in January 1982, Pakistan adopted managed floating exchange rate system.

Widespread financial liberalization initiated in 1989 led to exchange market reform and capital account liberalization, debt market strengthening, and revisions in banking laws. This followed by the second generation of reforms, pledged in 1999, and after the nuclear test that led Pakistan to freeze the resident foreign currency accounts. Subsequently, multiple exchange rate system was introduced, which was gradually unified where the market forces were expected to determine the value of the Rupee. However, effort to liberalize the exchange rate was aborted soon and a band was imposed on banks it was unofficial band, it remained unchanged for about a year. It was in total abandoned on 20th July 2000 as it was a part of an IMF program. The next few years were consolidation period for the reforms initiated in the exchange rate market. For this reason, this paper uses the exchange rate information from 2003.

Interestingly, SBP continued to intervene in the market to maintain the orderly condition that is; to prevent the speculative activity, to fill the gap arising out of the mismatches in import demand and export proceeds the forex transactions, and to support the FX market by directly meeting the foreign exchange requirements partially or fully for import of POL and debt payments. These reforms, though set the direction of the FX 
market development, its depth remains very thin in terms of turnover. Tightly managed FX market comes under pressure very often due to excess demand for the US dollar, leading to unidirectional buildup of expectations. The lack of depth and liquidity that provides stability in times of volatility leads to sharp overshooting and unidirectional trends, due to which the SBP intervention has becomes predictable to stabilize the market.

The shallow foreign exchange market and volatility in FX rate has restricted also the convertibility of the capital account despite the fact that most of the policies restricting the outflow of the capital were withdrawn. Still, there are some restrictions in place. For example, there are limits on the amount of domestic currency that an overseas traveler may physically carry (PKR500 to India and PKR3, 000 to other countries). Moreover, the amount a resident Pakistani may hold in overseas bank accounts is restricted to a maximum of USD1, 000. Apart from these, a residents or non-residents can open foreign currency accounts at commercial banks with remittances from abroad, foreign travelers' cheques, or foreign currency in cash, but not with income from export or similar activities. These features of Pakistan's economy suggest that the uncovered interest rate parity is less likely to prevail for this country.

\section{Review of the Recent Literature}

Uncovered Interest rate Parity (UIP) has given more attention and remained one of the most researched topics within the domain of the International Economic, and remains appealing to the researchers even after a spawn of papers has been generated on this subject. Literature on UIP is consensual that holding of this theory is more controversial in the advance economies, specifically in short term horizon [for example, Adilzhan and Barbara (2018), Vasliyev et al. (2017), Cuiabano and Divino (2010), Huisman (1998), King (1998), Pasricha (2006), Froot and Thaler (1990)] thanin the developing and the emerging economies. Moreover, the economic literature is in agreement that the hypothesis generally holds over the longer term horizon [for example, see Chinn and Meredith (2004, 2005), Lothian and Wu(2003), Dreger (2010) Fujii and Chin (2001), McCallum (1994), Cheung et al. (2005), Mehl and Capiello (2007)]. As the scope of this study is limited to Pakistan, the subsequent discussion therefore focuses only on the developing and the emerging economies, and then on Pakistan.

Despite broader consensus, UIP studies on emerging market economies also provides mix picture. Francis et al. (2002) argues that deviation from UIP in the group of emerging markets economies, including Pakistan, India, Korea, Mexico, Colombia, Chile, is systematic in nature and that a significant part of emerging market currency excess returns is attributable to time-varying risk premium. Frankel and Poonawala (2010) also studied the holding of UIP in group of advanced and emerging economies. Their findings suggest that the slope coefficient is on average positive, showing a right direction for forward discount in case of emerging market economies. They concluded that the time varying risk premium may not be the explanation for defining bias, instead, intrinsic riskiness of emerging market economies could be the driver of this bias. Alper et al. (2007) have surveyed the literature on UIP from developing and emerging economies, and concluded that the latter needs special treatment for UIP studies due to the existence of additional types of risk premium borne by weak macroeconomic conditions, underdeveloped financial markets and incomplete institutional reforms. Contrary to these findings, Vasliyev et al. (2017) have tested this condition for Russia and has generalized their findings for group of advanced and emerging economies. Their results confirm that UIP holds in Russia when it accounts for constant risk premium. These authors have concluded that UIP holds better in emerging market economies when constant risk premium is assumed. Moreover, while assessing the impact of different time horizon, Sarmidi and Salleh (2011) reported that UIP model has better econometric specification at the long term horizon and has more predictive power compared to the short time period.

Contrary to the favorable findings discussed above, Chinn (2006), who studied the holding of this hypothesis in group of non-G-7 countries, suggest that evidence against UIP is very convincing. Moreover, Mehl and Cappiello (2007) while assessing this hypothesis over long- and medium-term horizons, has 
found support in favor of the standard linear specification of UIP for dollar rates vis-à-vis major floating currencies, but not vis-à-vis emerging market currencies.

For the country specific studies this outcome is not very different. For example, Lily et al. (2011) has reported positive slope coefficient for Malaysia-UK and Malaysia-Japan, while negative coefficient for Singapore. These authors reported presence of a significant ARCH and GARCH effect in case of Singapore. On the contrary, the estimated long-run coefficients of Tang (2011), who assessed this hypothesis in ASEAN-5 economies, suggest that UIP holds only for Singapore but not for the rest of the selected ASEAN-5 economies. The author argued that the Singapore financial market is highly integrated with the US market while that of others are not fully liberalized and, therefore, have limited integration with international financial market.

Results of Deniz (2007), Shrestha (2014) and Melander (2009) show that UIP doesn't hold in a number of developing economies. Precisely, Deniz (2007) shows that for Turkey, UIP does not hold due to presence of significant ARCH and GARCH effect, while Shrestha (2014) failed to find evidence for UIP for emerging economies; Mexico and Brazil. Similarly, Melander (2009) also shows that the UIP does not hold for Bolivia due to peso problem, time varying risk premium, and deviation from rational expectations.

The economic literature assessing UIP holding in Pakistan is very limited and mostly has tested UIP either jointly with PPP or with forward risk premium. For example, Arshed and Haseeb (2013) while assessing the performance of CHEERs based equilibrium exchange rate, tested UIP conjointly with PPP and concluded that both parities work to explain exchange rate in long run. However, their findings suggest that the convergence to equilibrium after any shock is very slow. Similarly, Rashid and Husain (2012) have jointly tested UIP with PPP while modeling the exchange rate movements. Their results suggest a significant long run relationship among exchange rate, price and interest rate differential. Moreover, the coefficient of error correction term reveals substantial convergence towards long-run equilibrium. In line with this, Rashid (2012) has tested the UIP together with PPP and random walk for Pakistan. The results reveal that interest rate differential is significant determinant of exchange rate expectations in the long run. Furthermore, Khan et al., (2007) has tested presence of UIP between SAARC countries and US dollar. The results suggest strong cointegration in all these countries. While most of the above studies has used real exchange rate, our research is a contribution in UIP literature of Pakistan, as it uses actual nominal exchange rate for testing this hypothesis.

\section{Background Theory and Methodology}

Assuming interest rate parity holds, investors will be indifferent for return on securities in two countries, whether the position is covered or uncovered, as the future exchange rate between these two currencies should change by exactly the interest-rate differential. In the case of covered interest rate parity, the domestic interest rate, $\mathrm{rt}$, is represented as:

$r_{t}=r_{t}^{*}+f_{t}-s_{t}$

Where $\mathrm{r}_{\mathrm{t}}{ }^{*}$ is foreign interest rate, $\mathrm{f}_{\mathrm{t}}$ is forward rate and $\mathrm{s}_{\mathrm{t}} \mathrm{is}$ the spot rate. As UIP is uncovered parity, forward rate is replaced by the expected future exchange rate and forecast error,

$f_{t}=E\left(s_{t+i}\right)+\varepsilon_{t+i}$

Equation (1) can be written as

$r_{t}=r_{t}^{*}+E\left(s_{t+i}\right)-s_{t}+\varepsilon_{t+i}$ 
Following the literature on UIP, we assume that individuals have perfect foresight that is, $\mathrm{E}\left(\mathrm{s}_{\mathrm{t}+\mathrm{i}}\right)=\mathrm{s}_{\mathrm{t}+\mathrm{i}-}$ therefore equation (3) can be written as

$r_{t}=r_{t}^{*}+s_{t+i}-s_{t}+\varepsilon_{t+i}$

By rearranging, we get

$$
\mathrm{s}_{\mathrm{t}+\mathrm{i}}-\mathrm{s}_{\mathrm{t}}=\mathrm{r}_{\mathrm{t}}-\mathrm{r}_{\mathrm{t}}^{*}+\varepsilon_{\mathrm{t}+\mathrm{i}}
$$

For estimation purpose equation can be written as

$\mathrm{s}_{\mathrm{t}+\mathrm{i}}-\mathrm{s}_{\mathrm{t}}=\alpha+\beta\left(\mathrm{r}_{\mathrm{t}}-\mathrm{r}_{\mathrm{t}}^{*}\right)+\varepsilon_{\mathrm{t}+\mathrm{I}}$

Here by taking the assumptions of rational expectations in exchange markets and risk-neutrality among the investors, $\alpha$ must be zero while $\beta$ must be equal one. However, if investors are irrational or risk averse then this condition will be violated (MacDonald and Taylor, 1992).

For testing the UIP hypothesis, we investigated the data generating process of the interest and exchange rate differential series. For this purpose, we employed generic unit root tests, such as Augmented Dickey Fuller (ADF) and Phillips-Perron (PP) tests. Once the order of integration is established between the series that is, variables of interest are integrated or following I(1) processes, Johansen Cointegration test is used to assess the presence of long run relationship between them.

Developed by Johansen and Juselius $(1990,1992,1994)$ Johansen's cointegration test is essentially a rank test assessing the presence of long run relationship between the variables in a vector autoregressive process. Any $\operatorname{VAR}(\mathrm{p})$ can be presented in VECM form as,

$$
\Delta y_{t}=v+\Pi y_{t-1}+\sum_{i=1}^{p-1} \Gamma_{i} \Delta y_{t-i}+\varepsilon_{t}
$$

where $y_{t}$ is a $\mathrm{K} \times 1$ vector of variables, $v$ and $\varepsilon_{t}$ are $\mathrm{K} \times 1$ vector of parameter with errors that are normally distributed means serially uncorrelated but has contemporaneous covariance matrix. $\Pi=\sum_{j=1}^{j-p} A_{j}-$ $I_{k}$ and $\Gamma_{i}=-\sum_{i=k+1}^{j=p} A_{j}$. Here $A_{i}-A_{p}$ are $K \times K$ matric of autoregressive parameters. As matrix $\Pi=\alpha \beta^{\prime}$, where $\alpha$ and $\beta$ are parameter matrices of $(\mathrm{K} \times \mathrm{r})$ with rank $\mathrm{r}<\mathrm{K}$, Johansen rank test, using an ML estimator for the parameters, for inference o $\mathrm{r}$ it provides two likelihood-ratio (LR) tests. These Likelihood-ratio tests are known as the trace statistic and the maximum-eigen value statistic. Let $\lambda_{1}, \ldots, \lambda_{\mathrm{k}}$ be the optimum $\mathrm{K}$ eigen values computed from the log likelihood and are arranged from the largestto the smallest i.e. from $\lambda_{1}$ to $\lambda_{\mathrm{k}}$ respectively. If there exist $\mathrm{r}<\mathrm{K}$ cointegrating equations, then in this situation $\alpha$ and $\beta$ have rank $\mathrm{r}$ and the eigen values $\lambda_{\mathrm{r}+1}, \ldots, \lambda_{\mathrm{k}}$ are zero. Trace statistic takes the $\mathrm{H}_{0}$ i.e. null hypothesis, the hypothesis can be explained as that there are no more than $\mathrm{r}$ cointegrating relations. By limiting the cointegrating equations to $\mathrm{r}$ or lesser number implies that the remaining $\mathrm{K}-\mathrm{r}$ eigen values are zero. For any given value of $\mathrm{r}$, large values of the trace statistic are evidence against the null hypothesis that there is $r$ or fewer cointegrating relations in the VECM.

Contrary to the trace statistic, the maximum-eigen value statistic assumes a given $\mathrm{r}$ under the null hypothesis and tests this against the alternative that there are $r+1$ cointegrating equations. The test is known as the maximum-eigen value statistic as the element of the $\log$ likelihood function that changes with $\mathrm{r}$ is a simple function of the eigen values of a $(\mathrm{K} \times \mathrm{K})$ matrix. This method is used less comparative to trace statistic method because solution to the multiple-testing problem has not been found yet. 
Once presence of long run cointegrating relationship is established, the parameters of this relationship is estimated using dynamic ordinary least square (DOLS), provided by Stock and Watson (1993). Johansen Method of estimating parameters may suffer from misspecification in equations as this is a full information technique. DOLS provides consistent and efficient estimates of the long run relationship between the differenced stationary variables by augmenting optimal lead and lags of the integrated variables.

$\mathrm{y}_{\mathrm{it}}=\alpha_{\mathrm{i}}+\beta_{\mathrm{i}} \mathrm{x}_{\mathrm{it}}+\sum_{j=-q}^{q} \Pi i j \Delta \mathrm{x}_{\mathrm{ij}}+\mathrm{v}_{\mathrm{it}}$

Where $\mathrm{q}$ and $-\mathrm{q}$ are representing lag and leads used in the estimation of dynamic OLS. $\beta$ in this equation is DOLS estimator.

\section{Data Description}

For the UIP assessment, US dollar exchange rate against Pak rupee has been used, as Pakistan balance of payment is US dollar denominated. Our monthly data starts from March 2003, and ends at March 2019. The choice of the starting period is hinged on foreign exchange market consideration that largely remained unstable during 2000-2002 due to frequent experiment with various exchange rate regimes. Moreover, we assume perfect foresight and used actual, instead of the expected future, exchange rate. Since exchange rate differential is calculated by differencing $s_{t}$ from $s_{t+1}$, this may entail loss of some degrees of freedom. As our sample size is large enough, this will not affect our estimates.

Moreover, this research has benefitted with the three different definition of the exchange rates published by the State Bank of Pakistan; weighted average exchange rate, Kerb exchange rate, and Mark to Market (M2M) exchange rate. ${ }^{1}$ Apart from Kerb rate, data generating processes of the interbank rate are slightly different, and these are used for different purposes. For example, Weighted Average Exchange Rate (WAER) is weighted average estimate of exchange rates quoted by selected commercial banks to their clients for routine transactions. SBP obtains exchange rates quotation before 11:30 a.m. and calculates the average exchange rate for the day by multiplying the assigned weight of the bank with its quote. Kerb (or Open) market rate, on the other hand, is the exchange rate quoted by exchange companies to their customers.

SBP obtains the open market exchange rate quotation sheet from Exchange Companies Association of Pakistan (ECAP) at the close of the day. Finally, Mark to Market (M2M) exchange rate is the weighted average estimate of exchange rates quoted by authorized brokers in the interbank FX market for interbank transactions. SBP obtains quotation from authorized brokers before 1:30 p.m. and calculates the exchange rate by multiplying the assigned weights with exchange rates quoted by the brokers. These exchange rates are used by the authorized dealers to revalue their books daily on mark-to-market basis. Despite being similar intrinsically, these interbank rates and the Kerb rate show deviation from each other. Therefore, the use of three different exchange rates provides robustness check for the estimates of this paper.

For domestic and foreign interest rates, wide array of money market instruments with maturities ranging from 1-month to 10-years have been used i.e. (1-month, 3-month, 6-month, 1-year, 2-year, 3- year, 5-year, 7-year and 10-year) have been used. For domestic market interest rate, we use PKRV (Pakistan Revaluation Rate), a benchmark for the government securities computed by money market dealer on daily basis. For the foreign interest rate, we use daily US treasury yield in matching tenure. These data are averaged to use it as monthly interest rate data. Interest rate differential is calculated by differencing foreign from the domestic interest rates of similar maturities.

\footnotetext{
${ }^{1}$ The dailyweightedaveragecustomer exchange rates are published on SBP'swebsite, availableathttp://www.sbp.org.pk/ecodata/rates/war/WAR-Current.asp
} 


\section{Results and Discussion}

Generally, time series analysis requires stationarity check of the data series involved in estimation. We use Augmented Dickey Fuller (ADF) and Phillips Perron (PP) unit root tests for this purpose, at both level and first difference. Table A1 (in Appendix) show the result of the unit root tests. The null hypothesis that the series has a unit root (non-stationary) at level cannot be rejected for the interest rate differential series for all maturities ranging from 1-month to 10-year. However, the null hypothesis has been rejected at first difference for all maturities suggesting that these series are I (1) [results could be provided on request].

Similarly, the unit root tests reject the null hypothesis for 1-m, 3-m and 6-m maturities for exchange rate differentials (M2M, Kerb and WAER) series indicating that these maturities are stationary at level. ${ }^{2}$ However, for rest of the data series above 6-m maturities, the null hypothesis that the series has unit root could not be rejected. For the first difference of these series, the null hypothesis is rejected suggesting that maturities above 6-m are following I(1) processes [results can be provided on request].As both the interest and exchange rate differential series above 6-m (1-y, 2-y, 3-y,5-y, 7-y and 10-y) have same order of integration i.e., I(1), presence of long run relationship between the interest and the exchange rate differential series could be assessed, which is a necessary but may not be sufficient condition for the holding of UIP. The remaining series, of 6-m maturities or below, are not suitable for any meaningful analysis due to the difference in their order of integration and hence ignored for upcoming analysis.

Table 1: Johansen's Rank Test Result

\begin{tabular}{|c|c|c|c|c|c|}
\hline \multirow{2}{*}{ Tenure } & \multirow{2}{*}{ Optimal Lag } & \multicolumn{2}{|c|}{$\mathbf{r}=\mathbf{0}$} & \multicolumn{2}{|c|}{$\mathbf{r}=1$} \\
\hline & & Trace & Max stats & Trace & Max stats \\
\hline \multicolumn{6}{|c|}{ With Weighted Average Exchange Rate } \\
\hline 1-year & 2 & 7.1237 & 4.7125 & 2.4112 & 2.4112 \\
\hline 3-year & 20 & 5.7719 & 3.7161 & 2.055 & 2.0558 \\
\hline 5-year & 2 & 13.0921 & 8.4953 & $4.5969 *$ & $4.5969^{*}$ \\
\hline 7-year & 2 & 2.1459 & 1.9383 & 0.2076 & 0.2076 \\
\hline 10 -year & 5 & $17.548^{*}$ & 17.4168 & 0.1312 & 0.1312 \\
\hline \multicolumn{6}{|c|}{ With Mark to Market Exchange Rate } \\
\hline 1-year & 2 & 6.8363 & 5.0154 & 1.8209 & 1.8209 \\
\hline 3-year & 2 & 7.6475 & 5.6211 & 2.0265 & 2.0265 \\
\hline 5-year & 2 & $18.7862 *$ & 13.7654 & 5.0208 & 5.0208 \\
\hline 7-year & 2 & 2.1339 & 1.9896 & 0.1433 & 0.1443 \\
\hline 10 -year & 2 & $18.1805^{*}$ & $16.5759 *$ & 1.6046 & 1.6046 \\
\hline \multicolumn{6}{|c|}{ With Kerb Exchange Rate } \\
\hline 6-month & 7 & 9.3293 & 7.5569 & 1.7724 & 1.7724 \\
\hline 1-year & 2 & 5.746 & 4.106 & 1.6401 & 1.6401 \\
\hline 3-year & 2 & 6.9794 & 5.2576 & 1.7219 & 1.7219 \\
\hline 5-year & 2 & $18.6295^{*}$ & 13.2683 & 5.3612 & 5.3612 \\
\hline 7-year & 2 & 2.2365 & 2.0227 & 0.2138 & 0.2138 \\
\hline 10 -year & 5 & $21.4611 *$ & $19.6981 *$ & 1.7629 & 1.7629 \\
\hline $5 \% \mathrm{CV}$ & & 15.41 & 14.07 & 3.76 & 3.76 \\
\hline
\end{tabular}

Note: $*, * * * * *$, shows $1 \%, 5 \%$, and $10 \%$ level of significance.

Table 1 shows the result of the Johansen's rank test, testing the presence of long run relationship between the interest rate and the exchange rate differential series. Top, middle and the bottom panel shows the results when WAER, M2M and Kerb exchange rate differential series is used respectively for testing the

${ }^{2}$ In case of WAER, 6-m seriesalso show properties of unit root and thereforesubjected to the Cointegrationrank test. 
long run relationship. In all three panels, the trace statistics for the 10 -year maturity is greater than 5 percent critical value suggesting that the no long run relationship hypothesis $(r=0)$ between the exchange rate and the interest rate differential series is rejected. However, the null hypothesis of at most one cointegrating relationship $(\mathrm{r}=1)$ between the exchange rate and the interest rate differential series cannot be rejected.

Table 2: Error Correction and long run relationship between the Interest rate and Exchange rate Differential Series

\begin{tabular}{|c|c|c|c|c|c|c|c|}
\hline \multirow{3}{*}{ Tenure } & \multirow[b]{3}{*}{$\begin{array}{l}\text { Optimal } \\
\text { Lag }\end{array}$} & \multirow{2}{*}{\multicolumn{2}{|c|}{ Error correction }} & \multicolumn{4}{|c|}{ DOLS } \\
\hline & & & & \multicolumn{2}{|c|}{ Slope Coefficient } & \multicolumn{2}{|c|}{ Test for Beta $=1$} \\
\hline & & $\begin{array}{l}\text { ECM } \\
\text { Coefficient }\end{array}$ & p-value & Beta & p-value & Chi- Sq & p-value \\
\hline \multicolumn{8}{|c|}{ With Mark to Market Exchange Rate } \\
\hline 5-year & 2 & -0.047 & $(0.002)$ & -0.469 & $(0.166)$ & 18.820 & $(0.000)$ \\
\hline 10-year & 2 & -0.176 & $(0.050)$ & 0.625 & $(0.012)$ & 2.290 & $(0.130)$ \\
\hline \multicolumn{8}{|c|}{ With Kerb Exchange Rate } \\
\hline 5-year & 2 & -0.530 & $(0.002)$ & -0.360 & $(0.264)$ & 17.820 & $(0.000)$ \\
\hline 10-year & 5 & -0.133 & $(0.066)$ & 0.682 & $(0.011)$ & 1.410 & $(0.235)$ \\
\hline \multicolumn{8}{|c|}{ With Weighted Average Exchange Rate } \\
\hline 5-year & 2 & -0.041 & $(0.029)$ & -0.399 & $(0.280)$ & 14.360 & $(0.000)$ \\
\hline 10-year & 5 & -0.207 & $(0.016)$ & 0.709 & $(0.012)$ & 1.070 & $(0.301)$ \\
\hline
\end{tabular}

Note: estimated results of ECM and DOLS based on equation (7) and (8).

Besides the 10-y maturity, the null of no cointegrating relationship ( $r=0)$ is also rejected for the 5-y maturity and that of at most one cointegrating relationship $(r=1)$ cannot be rejected when exchange rate series from M2M and Kerb market is used (middle and bottom panels). Presence of long run relationship between the exchange rate and the interest rate differential series suffices the precondition of the holding UIP between the integrated series. The next step is to assess the nature of the relation between the interest rate and exchange rate differential series of 5- and 10-y maturities. For this purpose, we use Dynamic Ordinary least Square (DOLS). Rest of the maturities does not show any cointegrating relationship, hence uncovered interest rate parity doesn't hold in these maturities.

Table 2, provides the Error Correction (ECM) estimates and DOLS estimates. The error correction coefficients are significantly negative, enforcing the results obtained in Table 1 on presence of the long run relationship between the interest rate and exchange rate series. These ECM coefficients further suggest that speed of adjustment between in the series is very slow if system received any shock.

To obtain the DOLS estimates, we use optimal lead and lag by employing Hannn-Quinn (HQ) criteria. For the 5-y maturity, DOLS estimates suggest that $\beta$-coefficient is insignificant for all three exchange rate series. Moreover, test for the null hypothesis that $\beta=1$ is also rejected. Therefore, any shock to the interest rate differential doesn't bring equivalent change in the exchange rate over five-year period. In other words, UIP doesn't hold for the 5-y maturity instruments.

For the 10-y maturity, $\beta$-coefficient is significant and positive when using any of the three exchange rate. Moreover, the null hypothesis $\beta=1$ cannot be rejected in all three cases suggesting that any shock to the interest rate differential series brings proportional change in the exchange rate over the 10- year period. These results suggest that UIP in Pakistan holds but only over the longer horizon, that is 10-year. Our result finds support from Chinn and Meredith (2004) and Cheung et al. (2005): both concluded that the exchange rate is better predicted by the long term interest rates.

Our result that UIP does not hold for Pakistan for short to medium term maturities is not very intriguing. Central bank's intervention in the foreign exchange market restricts the fundamental based movements in 
the exchange rate in the short to the medium term. Waheed (2007) also noted the intervention of Central banks in foreign exchange market in emerging economies, particularly in Pakistan, has a direct consequence for the stance of monetary policy. However, over the longer horizon, the market fundamentals dictate the price discovery guiding the exchange rate to converge to its long run equilibrium. That is, in contrast to short term, macroeconomic adjustment over the long term leads to the movement in the exchange as predicted by the Uncovered Interest rate parity condition.

\section{Conclusion}

This research is an attempt to contribute to the literature by providing direct empirical assessment of UIP hypothesis for Pakistan. Using Johansen's Co-integration and Dynamic Ordinary Least Square (DOLS) on different maturities ranging from 1 month to 10 years, our results suggest that the UIP doesn't hold for Pakistan for short to medium term maturities, but holds only for the long term maturity that is 10 -year.

Less flexibility in the management of managed floating exchange rate regime adopted by the central bank hinders the convergence of the exchange rate to its long run equilibrium. State Bank's intervention to stabilize exchange rate distorts the price discovery mechanism in the foreign exchange market, at least in the short to medium run. As exchange rate acts as first line of defense for the monetary policy and management, the distortion in the exchange rate increases the vulnerability of the economy to the external shocks. It is not surprising that Pakistan's economy has continued to witness frequent balance of payment crisis. As policy proposal, our result suggests that more flexibility should be adopted in the exchange rate management of the country.

\section{References}

Adilzhan, I., and R. Barbara. (2018). Uncertainty and deviations from uncovered interest rate parity, Journal of International Money and Finance, 88(C): 242-259.

Alper, C.E., O.P.Adric., S. Fendoglu. (2007). The Economics of Uncovered Interest Rate Parity Condition for Emerging Markets: A Survey, MPRA Paper No. 4079, 15 July 2007.

Arshed, N., and Haseeb, M. (2013). Performance of CHEERs Based Equilibrium Exchange Rate of Pakistan, Business and Management Horizons, 1(1), 17 - 43.

Bansal, R. and M. Dahlquist. (2000). The Forward Premium Puzzle, Different Tales from Developed and Emerging Economies, Journal of International Economics, 51, 115-144.

Chaun, A. (2003). The Impact of liberalization on Uncovered Interest Rate Parity, University Putra Malaysia.

Cheung, Y.W., M.D. Chinn., G. A. Pascual. ( 2005) . Empirical exchange rate models of the nineties, are any fit tosurvive? Journal of International Money and Finance, 24, 1150-1175.

Chinn, M. D., and G. Meredith. (2004). Monetary Policy and Long Horizon Uncovered Interest Parity,IMF Staff Papers, 51(3), 409-430.

Chinn, M. D., and G. Meredith. (2005). Testing Uncovered Interest Parity at Short And Long Horizons During The Post-Bretton Woods Era, NBER Working Paper 11077.

Chinn, M.D.,(2006). The (Partial) Rehabilitation of interest rate parity in the floating rate era: Longer Horizons, alternative expectation and Emerging Markets, Journal of International Money and Finance, 25(1), 7-21.

Cuiabano, S. M and J. Divino. (2010). Exchange rate determination: an application of a monetary model for Brazil ,International Atlantic Economic Society, DOI: 10.1007/s11294-010-9276-X.

Dreger, C., (2010). Does The Nominal Exchange Rate Regime Affect the Real Interest Parity Condition? North American Journal of Economics and Finance, 21(3), 274-285.

Flood, R.P and A.K. Rose. (1994). Fixes: Of the Forward Discount Puzzle, National Bureau of Economic Research, working Paper number.4928.

Frankel, J. andPoonawala, J. (2010). The Forward Market in Emerging Currencies: Less Biased than in Major Currencies ,Journal of International Money and Finance, 29(3), 585-598. 
Froot, K. A., R. H.Thaler. (1990). Anomalies: Foreign Exchange, Journal of Economic Perspectives,4, 179-192.

Goh, S. K., G.C. Lim and N. Olekaln.(2006). Deviations from uncovered interest parity in Malaysia, Applied Financial Economics, 16(10), 745-759.

Huisman, R., K. Koedijk., C. Kool and F. Nissen.(1998). Extreme support for uncovered interest parity,Journal of International Money and Finance, 17, 211-228.

Khan, M, Arshad.,Sajid, M, Zubair (2007). Integration of Financial Markets in SAARC Countries: Evidence Based on Uncovered Interest Rate Parity Hypothesis, MPRA Paper No.6751, 15 January 2008.

King, A (1998). Uncovered interest parity: New Zealand's post-deregulation experience, Applied Financial Economics, 8, 495-503.

Kirikos, D.G. (2004). A Reconsideration of Uncovered Interest Rate Parity Under Switching Policy Regimes, Economia Internazionale,57 (2),125-144.

Lily,J., M. Kogid., D.Mulok, R. Asid. (2012). Revisiting Uncovered Interest Rate Parity: An Empirical Testing Using Bound Test Approach", Procedia Economics and Finance, 2(45), 45-52.

Lothian, J.R., and L. Wu (2003). Uncovered Interest Rate Parity Over the Past Two Centuries, Journal of International Money and Finance, 30(3).

Mark, N.C and Y. Wu. (1998). Rethinking Deviations from Uncovered Interest Parity, The Economic Journal,108, 1686-1706.

Mehl, A and A, Cappiello. (2007). Uncovered Interest Rate Parity at Distant Horizon Evidence on Emerging Economies and Nonlinearities, European Central Bank Working Paper Series, No.801.

Melander, O. (2009). Uncovered Interest Parity in a Partially Dollarized Developing Country: Does UIP Hold in Bolivia? (And if not, Why not?), SSE/EFI Working Paper Series in Economics and Finance, No.716.

Pasricha, G.K .(2006). Survey of literature on covered and uncovered interestparities, MPRAPaper 22737.

Rashid, A. (2012). On the Exchange Rate Expectations: Does UIP Really beat PPP and Random Walks? , International Journal of Economics and Business Research, 4(3),346- 361.

Rashid, A. and Husain, F. (2012). On the Modeling of Exchange Rate: Some Evidence from Pakistan, MPRA Paper NO. 47547.

Sercu, P., M. Vandebroek, X. Wu. (2008). Is the forward bias economically small? Evidence from European rates ,Journal of International Money and Finance, 27, 1284-1302.

Si, D.K., C.W.Su., K.M.LU and S.C.Doong. (2017). Does the Uncovered Interest Rate Parity Hold? Evidence For Central and Eastern European Countries ,The Economic Research Guardian, 7(1), 24-39.

Skerman., Robert and Della., Daniel. (2009). Johansen Cointegration Analysis of American andEuropean Stock Market Indices: An Empirical Study, Lund Student Papers

Tang, K.B. (2011). The Precise form of Uncovered Interest Parity: A Heterogeneous Panel Application in ASEAN-5 Countries, Economic Modelling, Elsevier, vol. 28(1), 568-573.

Vasilyev, D., V. Busygin and S. Busygin. (2017). Testing and Interpreting Uncovered Interest Rate Parity in Russia ,Russian Journal of Economics, 3, 158-173.

Waheed, M. ( 2007). Central Bank Intervention, Sterilization and Monetary Independence: The Case of Pakistan, MPRA Paper NO. 2328

Yung, J. (2014). Can Interest Rate Factors Explain Exchange Rate Fluctuations? Federal Reserve Bank of Dallas, Working Paper No. 207. 


\section{Appendix}

Table A1. Unit Root Results for Interest rate Differential and Exchange rate Differentials

\begin{tabular}{|c|c|c|c|c|}
\hline & \multicolumn{2}{|c|}{ Dickey-Fuller test } & \multicolumn{2}{|c|}{ Phillips-Perron test } \\
\hline & Drift only & Drift with trend & Drift only & Drift with trend \\
\hline \multicolumn{5}{|c|}{ Interest rate differential series } \\
\hline 1 month & -0.952 & -0.889 & -1.12 & -1.096 \\
\hline 3 month & -0.814 & -0.761 & -1.081 & -1.085 \\
\hline 6 month & -0.768 & -0.758 & -1.077 & -1.115 \\
\hline 1 year & -0.776 & -0.8 & -1.107 & -1.167 \\
\hline 2 year & -2.76 & -0.447 & -2.509 & -0.501 \\
\hline 3year & -0.953 & -1.013 & -1.284 & -1.375 \\
\hline 5year & -1.032 & -1.203 & -1.347 & -1.534 \\
\hline 7year & -1.086 & -1.342 & -1.439 & -1.708 \\
\hline 10year & -1.13 & -1.486 & -1.484 & -1.852 \\
\hline 95\% Critical Values & -2.883 & -3.437 & -2.883 & -3.437 \\
\hline $90 \%$ Critical Values & -2.573 & -3.137 & -2.573 & -3.137 \\
\hline \multicolumn{5}{|c|}{ Exchange Rate Differentials } \\
\hline \multicolumn{5}{|c|}{ Mark to Market Exchange Rate (M2M) } \\
\hline 1 month & $-11.558 * *$ & $-11.738 * *$ & $-11.812 * *$ & $-11.964 * *$ \\
\hline 3 month & $-4.782 * *$ & $-4.953 * *$ & $-5.162 * *$ & $-5.327 * *$ \\
\hline 6 month & -2.214 & -2.463 & $-3.579 * *$ & $-3.790 * *$ \\
\hline 252 & 0.394 & 0.049 & -1.354 & -1.593 \\
\hline 2 year & 0.473 & & -1.109 & -1.246 \\
\hline$(8)$ & -0.108 & -0.278 & -1.06 & -1.174 \\
\hline $5 y e a r$ & -0.469 & -0.743 & -1.029 & -1.229 \\
\hline $5>$ & 0.244 & -0.544 & -0.546 & -1.133 \\
\hline 10year & 0.779 & -1.677 & 0.329 & -2.026 \\
\hline $95 \%$ Critical Values & -2.884 & -3.438 & -2.884 & -3.438 \\
\hline $90 \%$ Critical Values & -2.574 & -3.138 & -2.574 & -3.138 \\
\hline $408 x+2 y$ & \multicolumn{3}{|c|}{ Kerb (Open) Market Exchange Rate } & 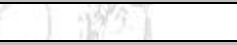 \\
\hline 1 month & $-12.285 * *$ & $-12.437 * *$ & $-12.410 * *$ & $-12.529 * *$ \\
\hline 3 month & $-5.386 * *$ & $-5.531 * *$ & $-5.606 * *$ & $-5.745 * *$ \\
\hline 6 month & $-2.652 *$ & -2.866 & $-3.945 * *$ & $-4.137 * *$ \\
\hline 1 year & -0.722 & -0.984 & -2.058 & -2.262 \\
\hline 2 year & -0.554 & -0.721 & -1.632 & -1.753 \\
\hline 3year & -0.561 & -0.724 & -1.299 & -1.418 \\
\hline 5year & -0.867 & -1.202 & -1.257 & -1.514 \\
\hline 7 year & -0.12 & -0.902 & -0.683 & -1.315 \\
\hline 10year & 0.337 & -1.927 & 0.14 & -2.101 \\
\hline $95 \%$ critical Values & -2.878 & -3.428 & -2.878 & -3.428 \\
\hline 90\%Critical Values & -2.57 & -3.13 & -2.57 & -3.13 \\
\hline \multicolumn{5}{|c|}{ Weighted Average Exchange Rate (WAER) } \\
\hline 1month & $-10.130 * *$ & $-10.237 * *$ & $-10.220 * *$ & $-10.306 * *$ \\
\hline 3 month & $-4.259 * *$ & $-4.279 * *$ & $-4.486 * *$ & $-4.511 * *$ \\
\hline 6 month & -2.240 & -2.426 & -2.822 & -2.991 \\
\hline 1 year & -0.281 & -0.494 & -0.954 & -1.103 \\
\hline 2 year & -0.144 & -0.089 & -0.976 & -0.901 \\
\hline 3 year & -0.871 & -0.713 & -1.376 & -1.277 \\
\hline $5 y e a r$ & -0.939 & -0.265 & -1.124 & -0.495 \\
\hline 7year & -0.493 & -0.08 & -0.792 & -0.411 \\
\hline 10year & -0.852 & -2.233 & -0.519 & -2.124 \\
\hline 95\% Critical Values & -2.886 & -3.442 & -2.886 & -3.442 \\
\hline $90 \%$ Critical Values & -2.576 & -3.142 & -2.576 & -3.142 \\
\hline
\end{tabular}

